\title{
ENSAIOS SOBRE A METODOLOGIA DO ESTUDO DA INFLUENCIA DE TRÊS HERBICIDAS EM Spirodela punctata (G.F.W. Meyer) Thompson (LEMNACEAE)
}

\author{
Durvalina Maria Mathias dos Santos 1
}

\begin{abstract}
RESUMO -O presente trabalho visa conhecer a taxa de multiplicação e o índice de mortalidade de S. punctata a diversas concentraçōes do butaclora, propanila e glifosato bem como comparar dois métodos diferentes de investigações (ensaio 1 e 2). Os dados indicaram que no ensaio 1 as concentrações foram pouco tóxicas provocando baixos indices de mortalidade embora tenha ocorrido inibição do crescimento nas concentrações mais fortes. O ensaio 2 mostrou que a butaclora e a propanila são mais tóxicas que o glifosato, com valores de mortalidade de $100 \%$ em apenas 48 horas. A taxa de multiplicação, neste ensaio, somente foi determinada para o glifosato, pois os demais herbicidas foram altamente tóxicos para a espécie. Verificou-se, na comparação dos dois métodos diferentes, que os recipientes utilizados no ensaio 2 foram mais adequados ao cultivo da espécie e que os efeitos tóxicos devem ser observados em frondes consideradas individualmente e não em plantas inteiras.
\end{abstract}

Palavras-chave: Spirodela punctata, Butaclora, Propanila, Glifosato, Crescimento.

\begin{abstract}
SUMMARY - The present work looks for a knowledge of multiplicate rate and mortality index of. S. punctata to several concentrations of butachlor, propanil and gliphosate as well as to compare two different methods. On essay 1 the concentrations were a little toxic provoking low index of mortality in spite of it has occured inhibition of increasing on stronger concentrations. The essay 2 showed what, the butachlor and the propanil are more toxics than the gliphosate, with values of mortality of $100 \%$ in only 48 hours. The multiplicate rate, on this essay, was only determinated to the gliphosate, because the other herbicides were highly toxic to the species. It was checked on the comparation of the two different methods the posts used on essay 2 were more appropriate to the cultive specie and the toxic effects must be observated on considered individualy and not on whole plants.
\end{abstract}

Key words: Spirodela punctata, Butachlor, Propanil, Gliphosate, Growth.

\section{Introdução}

Spirodela punctata (G.F.W. Meyer) Thompson, é uma planta flutuante que cresce na superfície da água. Considerada por vários autores (Palm 1968; Correll \& Correll 1975; Fryer \& Makepeace 1977; Metha 1979; Lorenzi 1982; Radosevich \& Holt 1984 e outros) como infestante de mananciais de água parada e de lagos, lagoas e represas, a espécie com seu vigoroso crescimento, entope canais e valetas, interferindo na sua utilização.

Margalef (1974) salienta que a vegetação aquática pode rapidamente tornar-se excessiva devido à alteração das condições e dos fatores ecológicos em determinados ambientes aquáticos, resultante ou não da ação humana.

O manejo da vegetação aquática é essencial para a preservação e utilização dos recursos hídricos. Um dos métodos de manejo consiste no uso de herbicidas como inibidores do excessivo crescimento das hidrófitas. De acordo com Saggers (1976), devido a sua susceptibilidade aos herbicidas, as plantas aquáticas são importantes para os estudos sobre a atividade biológica desses produtos, sendo freqüentemente empregadas em bioensaios e como indicadoras da poluição da água. Landolt \& Kandeler (1987) salienta-

\footnotetext{
${ }^{1}$ Departamento de Botânica - Instituto de Biociências - UNESP. 13.500 - Rio Claro, Av. 24-A n? 1515 - Bela Vista.
} 
ram que espécie de lemmáceas são capazes de tolerar um grau relativamente alto de poluição e que, às vezes, somente a vegetação de lemnáceas cresce vigorosamente em locais muito poluídos. Os autores descrevem que S. punctata é capaz de crescer em solução com $1 \mathrm{~g}$ de nitrogênio/litro e $1,5 \mathrm{~g}$ de fósforo/litro, indicando que é tolerante ao alto conteúdo de nutrientes. De um modo geral, as espécies são capazes de absorver e desintegrar substâncias tóxicas e acumular metais pesados.

Os efeitos dos herbicidas sobre as plantas aquáticas são amplamente documentados na literatura (Way \& Chancellor de 1976; Landolt \& Kandeler 1987). Vários produtos foram testados no controle de tais plantas, como os carbamatos (Shaw \& Swanson 1953), o diquat e o paraquat (O'Brien \& Prendeville 1978), o cianocrilate (Huppatz \& Phillips 1982) e muitos outros compostos (Slooff \& Canton 1984).

A respeito do crescimento do gênero Spirodela encontram-se trabalhos sobre a influência de vários produtos químicos (Hance \& McKone 1976; Rasol \& Rendic 1978. Sahai et al. 1983; Charpentier \& Garnier 1986, entre outros), porém, não há registro de qualquer estudo sobre os herbicidas investigados no presente trabalho e nem de produtos químicos afins.

Hillman (1961) em sua revisão sobre a família Lemnaceae indicou estudos de toxidade com vários tipos de herbicidas, principalmente em outra espécie, Lemna minor L.

Brian (1976) salienta que os herbicidas do grupo das amidas, ao qual pertencem a butaclora $^{2}$ e a propanila ${ }^{3}$, exercem sobre as plantas vários efeitos biológicos. A butaclora é utilizada em pre-emergëncia para o controle de monocotiledôneas e dicotiledôneas na semeadura e no transplante do arroz irrigado; a propanila controla plantas daninhas em culturas de arroz e batata. O glifosato 4 , que pertence ao grupo dos ácidos alifáticos (Camargo 1986) está sendo testado como um novo herbicida para o controle de plantas aquáticas; a amostra utilizada neste trabalho. foi cedidá pela Monsanto em caráter experimental.

O presente trabalho visa verificar as respostas da mortalidade e do crescimento de S. punctata aos três herbicidas acima citados.

\section{Material e Métodos}

\section{Obtenção do Material}

O material de S. punctata foi coletado em lagoas situadas no Bairro do Sobrado (município de Rio Claro, SP) e introduzido no hidrofitotério do Jardim Experimental do Instituto de Biociências da Universidade Estadual Paulista "Julio de Mesquita Filho" (UNESP) em Rio Claro. Uma amostra aleatória foi transferida para um laboratório do Departamento de Botânica daquele Instituto. As plantas foram separadas com pincel fino, em placas de Petri com água destilada e lavadas por várias vezes para remoção dos detritos. A seguir, as plantas foram mantidas durante $\mathbf{2 4}$ horas em bandejas de plástico contendo meio específico de Hutner (Tabela 1), que é o mais recomendado para o cultivo de lemnáceas (Hillman 1969). As soluções de herbicidas foram preparadas com este meio.

\section{Determinação da Mortalidade e do Crescimento}

Foram utilizados os termos "planta" para o indivíduo com frondes e raízes e "fronde" para cada fronde de uma mesma planta com várias frondes (Figura 1). Segundo Font Quer (1970), denomina-se fronde o corpo vegetativo talóide das lemnáceas. O termo é empregado, também, em pteridófitas, palmae, algas, etc. Desde que em cada planta tratada encontravam-se ao mesmo tempo frondes sadias (verdes), cloróticas (esbranquiçadas) e necrosadas (amarronzadas), foram consideradas para o cálculo da mortalidade, as plantas com todas as frondes necrosadas.

\footnotetext{
2Monsanto LQ nome comercial: MANCHETE $60 \%$ de ia. (butaclora)

${ }^{3}$ Rohm \& Hass LQ nome comercial: STAM M-4 48\% de ia. (propanila)

${ }^{4}$ Mosanto IQ nome comercial: RODEO $48 \%$ de ia. (glifosato)
} 
Tabela 1 - Composição do Meio de Hutner

\begin{tabular}{ll}
\hline Componentes & $\begin{array}{l}\text { quantidades } \\
(\mathrm{mg} / 1)\end{array}$ \\
\hline $\mathrm{K}_{2} \mathrm{HPO}_{4}$ & 400 \\
$\mathrm{KOH}$ & 200 \\
EDTA & 500 \\
$\mathrm{NH}_{4}, \mathrm{HO}_{3}$ & 200 \\
$\mathrm{Ca}\left(\mathrm{NO}_{3}\right)_{2} \cdot 4 \mathrm{H}_{2} \mathrm{O}$ & 354 \\
$\mathrm{MgSO}_{4} \cdot 7 \mathrm{H}_{2} \mathrm{O}$ & 500 \\
$\mathrm{FeSO}_{4} \cdot 7 \mathrm{H}_{2} \mathrm{O}$ & 24,9 \\
$\mathrm{MnCl}_{2} \cdot 4 \mathrm{H}_{2} \mathrm{O}$ & 17,9 \\
$\mathrm{ZnSO}_{4} \cdot 7 \mathrm{H}_{2} \mathrm{O}$ & 65,9 \\
$\mathrm{CuSO}_{4} \cdot 5 \mathrm{H}_{2} \mathrm{O}$ & 3,95 \\
$\mathrm{Na}_{2} \mathrm{MoO}_{4} \cdot 2 \mathrm{H}{ }_{2} \mathrm{O}$ & 25,2 \\
$\mathrm{H}_{3} \mathrm{BO}_{3}$ & 14,2 \\
\hline
\end{tabular}

Completar até 1 litro com água destilada

$\mathrm{pH}$ ajustado para 6,2-6,5 com $\mathrm{HCl} 0,1 \mathrm{~N}$

Foi seguido o critério de Offord (1946) que estabelece quatro tipos de reação, para determinar os sintomas de injúria e mortalidade quando as plantas aquáticas são submetidas a herbicidas.

Tipo 1 - Clorose e descoloramento das frondes; a cor típica das frondes injuriadas pode ser vermelho amarronzado, amarelo pálido ou branco.

Tipo 2 - Clorose em menor proporção mas uniforme em todas as frondes: a cor típica das frondes injuriadas pode ser amarelo pálido ou amarelo esverdeado.

Tipo 3 - Ruptura e desorganização das frondes: as frondes sofrem ruptura, desorganizam-se.

Tipo 4 - Aspecto sadio das frondes: cor típica verde-escura até que a falta de nutrientes, ação bacteriana ou prolongado contato com a solução de herbicidas causem injúria.

\section{Montagem dos Ensaios}

Foram executados dois ensaios sucessivos.

\subsection{Primeiro ensaio}

Foi executado em condições de laboratório, com temperatura média de $26+1^{\circ} \mathrm{C}$ e fotoperíodo de 11 horas no Claro (3000 lux) e 13 horas no escuro.

O material de $\mathbf{S}$. punctata foi colocado em placas de Petri com $9 \mathrm{~cm}$ de diâmetro e $1 \mathrm{~cm}$ de profundidade, contendo cada uma $20 \mathrm{ml}$ de meio de Hutner com as respectivas concentrações dos herbicidas. Foram colocados em cada placa 20 indivíduos com 4 frondes, num total de 80 frondes. Foram feitas quatro repetições para cada herbicida, num total de 28 placas com 560 plantas e 2240 frondes.

Para cada herbicida foi utilizada uma série logarítmica de sete concentrações: 0 (tes-

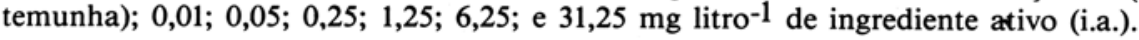

\subsection{Segundo ensaio}

$\mathrm{Na}$ tentativa de sanar os defeitos encontrados na metodologia do primeiro ensaio 
e verificar a tolerância de $\mathbf{S}$. punctata à concentrações mais fortes dos três herbicidas, foi feito o segundo ensaio que diferiu do primeiro no número de plantas, no uso de doses elevadas, na utilização de outros recipientes e nos fatores ambientais.

Este ensaio foi executado em câmara climática, a temperatura de $25^{\circ} \pm 1^{\circ} \mathrm{C}$, com umidade relativa de $60 \%$ e fotoperíodo de 12 horas no claro (4.500 lux) e $\overline{1} 2$ horas no escuro. O material de $\mathbf{S}$. punctata foi colocado em copos plásticos com $7 \mathrm{~cm}$ de altura, $8 \mathrm{~cm}$ de diâmetro superior e $4,5 \mathrm{~cm}$ de diâmetro basal, contendo cada um $150 \mathrm{ml}$ de meio de Hutner com as respectivas concentrações dos herbicidas. Foram colocadas em cada copo, 10 plantas para a butaclora, 50 para a propanila e 100 frondes para o glifosato, num total de 300 plantas e 500 frondes.

Para cada herbicida, foi utilizada uma série logarítmica de seis concentrações: 0 (tes-

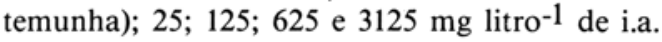

\section{Avaliação dos Resultados}

Nos ensaios foram avaliados o índice de mortalidade e o crescimento no período de 8 dias para o primeiro ensaio e 20 dias para o segundo ensaio. Nesses ensaios com duração de 20 dias, a avaliação ocorreu a cada 5 dias.

\subsection{Mortalidade}

O índice de mortalidade foi calculado pela fórmula de Abbott (1965):

onde:

$$
\% \text { M.C }=\frac{(\% \text { M.0 }-\% \text { M.T }) \times 100}{100-\% \text { M.T. }}
$$

MC. = mortalidade corrigida

M.O = mortalidade observada

M.T = mortalidade do tratamento testemunha

De acordo com o critério de Abbott (1965) para que seja empregada esta fórmula, a porcentagem da mortalidade da testemunha não deve ultrapassar a $20 \%$.

\subsection{Crescimento}

Para o cálculo do crescimento utilizou-se a fórmula descrita por Hillman (1961) e Rombach (1976):

T.M. $=10001 / \mathrm{T} \log 1 / \mathrm{T} \log \left(\mathrm{n}_{1} / \mathrm{n}_{\mathrm{O}}\right)$

onde:

T.M. = Taxa de multiplicação

$\mathrm{T}=\mathrm{T}_{1}-\mathrm{T}_{\mathrm{o}}$ (tempo final - tempo inicial)

$\mathrm{n}_{\mathrm{O}}=$ número de frondes iniciais.

$\mathrm{n}_{1}=$ número de frondes finais.

\section{Resultados e Discussões}

Os valores da taxa de multiplicação, em cada uma das concentrações usadas no primeiro ensaio, com os três herbicidas, encontram-se na Figura 2. Verifica-se que todos os tratamentos testemunha apresentaram valores elevados de crescimento $(72,1 \% ; 91,5 \%$ e $87,6 \%$ para a butaclora, propanila e glifosato, respectivamente). Nos tratamentos mais fortes $\left(6,25\right.$ e $31,25 \mathrm{mg}$ litro $\left.^{-1}\right)$ houve acentuada inibição do crescimento. Os demais tratamentos $\left(0,01 ; 0,05 ; 0,25\right.$ e 1,25 mg litro- $\left.^{-1}\right)$ apresentaram valores intermediários de inibição. Ficou claro, todavia, que as placas de Petri e o volume utilizado neste experimento $(20 \mathrm{ml})$, limitaram o crescimento, pois as plantas preencheram todo o espaço da placa em 8 dias, sugerindo que provavelmente a taxa de multiplicação teria sido maior se os 
recipientes fossem mais largos. Em relação a quantidade de solução $(20 \mathrm{ml})$ observou-se que, as plantas necessitavam de uma maior quantidade de meio e uma maior profundidade no recipiente para a sua flutuação. Como as raizes filiformes de S. punctata são longas, a pouca profundidade das placas de Petri $(1 \mathrm{~cm})$, provavelmente, dificultou a absorção dos nutrientes e herbicidas da solução. No decorrer dos experimentos, ocorreu também um aumento de raízes, que formaram um emaranhado. Segundo Hillman (1961) as raízes de lemnáceas possuem menos que $0,5 \mathrm{~mm}$ de diâmetro e o comprimento varia nas espécies até $14 \mathrm{~cm}$ dependendo das condições ambientais. Por outro lado, esse autor salientou ainda que a superfície abaxial das frondes pode absorver nutrientes do meio e que as plantas crescem satisfatoriamente na ausência de raízes. Realmente, a função das raízes de lemnáceas não foi ainda esclarecida completamente.

Tanto as áreas limitadas das placas de Petri quanto volume de meio utilizado, levaram ao encerramento do primeiro ensaio aos 8 dias. Após esse período os resultados tornaram-se confusos, não podendo ser interpretados. Durante os 8 dias ocorreram também, pequenas mudanças no $\mathrm{pH}$ do meio de cultura, embora Hillman (1961) tenha observado que as lemnáceas suportam faixas de $\mathrm{pH}$ de $4,5-7,5$. Quanto a temperatura, Hillman (1961) esclareceu que as temperaturas entre $20^{\circ} \mathrm{C}$ e $30^{\circ} \mathrm{C}$ são as mais favoráveis ao crescimento das lemnáceas em meio de Hutner. A luminosidade utilizada neste primeiro ensaio foi baixa, embora provavelmente não tenha influído nas respostas aos herbicidas. $\mathrm{O}$ mesmo autor verificou que as lemnáceas aparecem em todas as intensidades luminosas e o crescimento é independente da duração do período de luz. Bowker et al. (1980) utilizaram iluminação constante de 8.000 a 12.000 lux e Rombach (1976) usou luz contínua em vários espectros de ação. o.

Os valores de mortalidade, no primeiro ensaio, apresentaram-se relativąmente baixos não ultrapassando $40 \%$ (Figura 3). Os tratamentos mais fortes $(6,25$ e $31,25 \mathrm{mg}$ li-

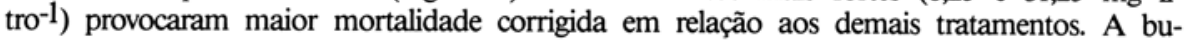
taclora apresentou índice de mortalidade maịor do que os outros dois herbicidas, a partir da concentração de $0,25 \mathrm{mg}$ litro ${ }^{-1}$. O glifosato provocou os menores índices de mortalidade, mesmo nas concentrações mais fortes. Diante dos baixos valores encontrados para a mortalidade, pode-se sugerir que a metodologia utilizada neste primeiro ensaio não interferiu neste índice pelo menos em 8 dias. Em relação ao segundo ensaio, salienta-se que as plantas pertenciam ao mesmo lote da coleta de plantas utilizadas no primeiro ensaio. Neste ensaio, a adoção de copos plásticos em formato de tronco de cone possibilitou utilizar pouca quantidade de solução, que permitiu a livre flutuação das plantas. Apesar do diâmetro dos copos $(8 \mathrm{~cm})$ ser menor do que o das placas de Petri $(9$ $\mathrm{cm})$, as plantas não cresceram a ponto de preencher os espaços disponíveis. Isto sugere que as concentrações de herbicidas utilizadas neste segundo ensaio influíram no crescimento. Os resultados da taxa de multiplicação com butaclora e propanila não puderam ser determinados, devido aos altos índices de mortalidade. De fato, os valores do índice de mortalidade para a butaclora e propanila (Figura 4) são extremamente altos. Tais herbicidas apresentaram, em apenas dois dias, $100 \%$ de mortalidade corrigida no tratamento mais forte (3125 mg litro ${ }^{-1}$ ) e mesmo nas concentrações mais baixas houve elevada mortalidade. No caso do glifosato entretanto, houve apenas $9 \%$ de mortalidade na concentração de $3.125 \mathrm{mg}$ litro ${ }^{-1}$, valor bem menor do que nos demais herbicidas. As frondes que permaneciam vivas nesse tratamento, apresentaram o tipo de reação 3, descrito por Offord (1946), (vide pág. 269 deste trabalho). Na concentração de $625 \mathrm{mg}$ litro-1, a butaclora em apenas 2 dias teve efeito mais tóxico (90\%) do que os demais herbicidas, além de se constatar sintomas do tipo 1 e 3 nas plantas vivas. Após 3 dias, este tratamento atingiu $100 \%$ de mortalidade. O efeito da propanilä, nesta concentração (625 mg litro-1), foi menor, porém atingiu $100 \%$ de mortalidade aos 5 dias. O glifosato apresentou apenas $30 \%$ de mortalidade aos 20 dias. A concentração de $125 \mathrm{mg} \mathrm{litro}^{-1}$ e $25 \mathrm{mg} \mathrm{litro}^{-1}$ de butaclora provocaram $100 \%$ de mortalidade em 10 dias. Para a propanila, tais con- 
centrações ocasionaram $100 \%$ de mortalidade em 10 e 15 dias, respectivamente. Nos tra-

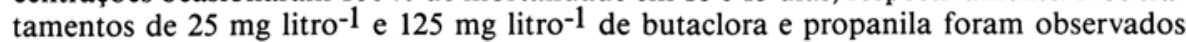
os sintomas do tipo 1 e 3 . Nenhum dos herbicidas em nenhum tratamento provocou nas frondes de $\mathbf{S}$. punctata os sintomas descritos no tipo 2. O glifosato, nas concentrações de 625,125 e $25 \mathrm{mg}^{\text {litro- }}{ }^{-1}$, provocou após 20 dias, todos os tratamentos inibiram o crescimento da espécie. Aos 25 dias todos os tratamentos, inclusive a testemunha, apresentaram os sintomas tipo 4. As testemunhas dos três herbicidas permaneceram com todas as plantas vivas e em crescimento até os 20 dias de ensaio. A Figura 5 mostra o efeito do glifosato sobre a taxa de multiplicação, pois este herbicida, nas concentrações utilizadas, não foi letal para a espécie. Aos 20 dias, os sintomas tipo 4. As testemunhas dos três herbicidas permaneceram com todas as plantas vivas e em crescimento até os 20 dias de ensaio. A Figura 5 mostra o efeito do glifosato sobre a taxa de multiplicação, pois este herbicida, nas concentrações utilizadas, não foi letal para a espécie. Aos 20 dias, todos os tratamentos inibiram o crescimento da espécie. Aos 25 dias todos os tratamentos, inclusive a testemunha, apresentaram os sintomas do tipo 4 , evidenciando que o tempo máximo para ensaios nas condições ambientais e meio de cultura utilizados neste trabalho não podem exceder a aproximadamente 25 dias de experimento.

Os resultados comparativos de dois métodos diferentes que determinaram a taxa de multiplicação e o índice de mortalidade nas diversas concentrações de herbicidas encontram-se na Tabela 2.

\section{Observações}

Quanto aos dois Métodos diferentes os resultados levaram a observar que:

1. As placas de Petri são inadequadas para os ensaios com $\mathbf{S}$. punctata devido a pequena profundidade $(1 \mathrm{~cm})$ que acarreta um menor volume de Meio para a planta. Os recipientes mais adequados são aqueles que tem pelo menos $5 \mathrm{~cm}$ de profundidade o que permite livre flutuação das frondes.

2. Todas as plantas de $\mathbf{S}$. punctata apresentam número variado de frondes. Desta forma, a dificuldade em se obter e mesmo separar 50 ou 100 indivíduos, todos com o mesmo número de frondes é muito maior do que se a contagem for efetuada por frondes individuais. Convém, portanto, escolher não um número exato de plantas mas um número exato de frondes. Diante desta conclusão, o experimento do glifosato foi montado com 100 frondes, desprezando-se o número real de plantas.

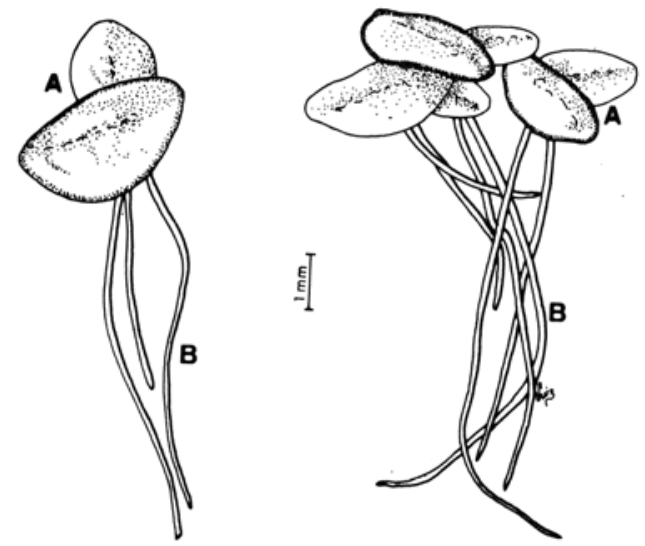

Figura 1. Spirodela punctata (G. F. W. Meyer) Thompson. Aspecto geral.
A. frondes
B. raizes 


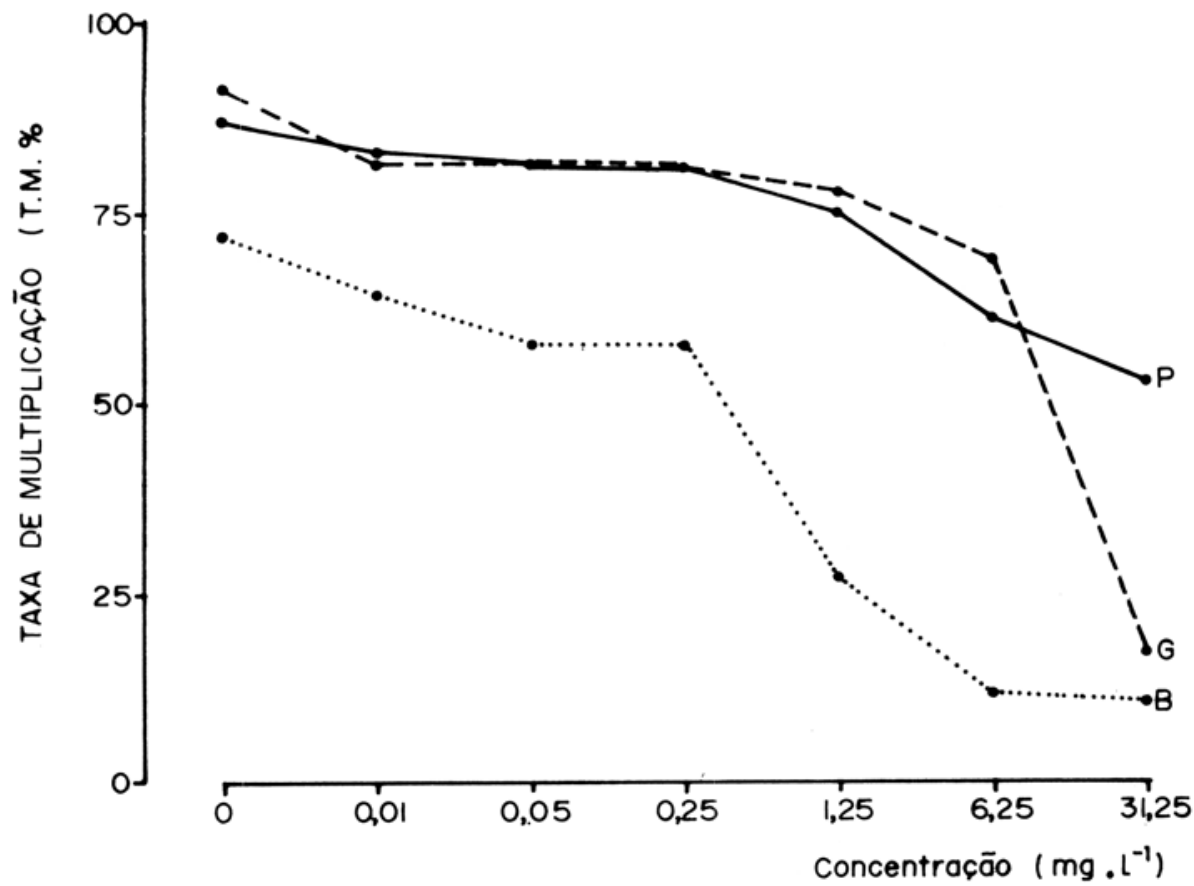

Figura 2. Crescimento de S. punctata (G. F. W. Meyer) Thompson, após 8 dias.
$\mathrm{B}=$ butaclora
$\mathrm{P}=$ propanila
$\mathrm{G}=$ glifosato
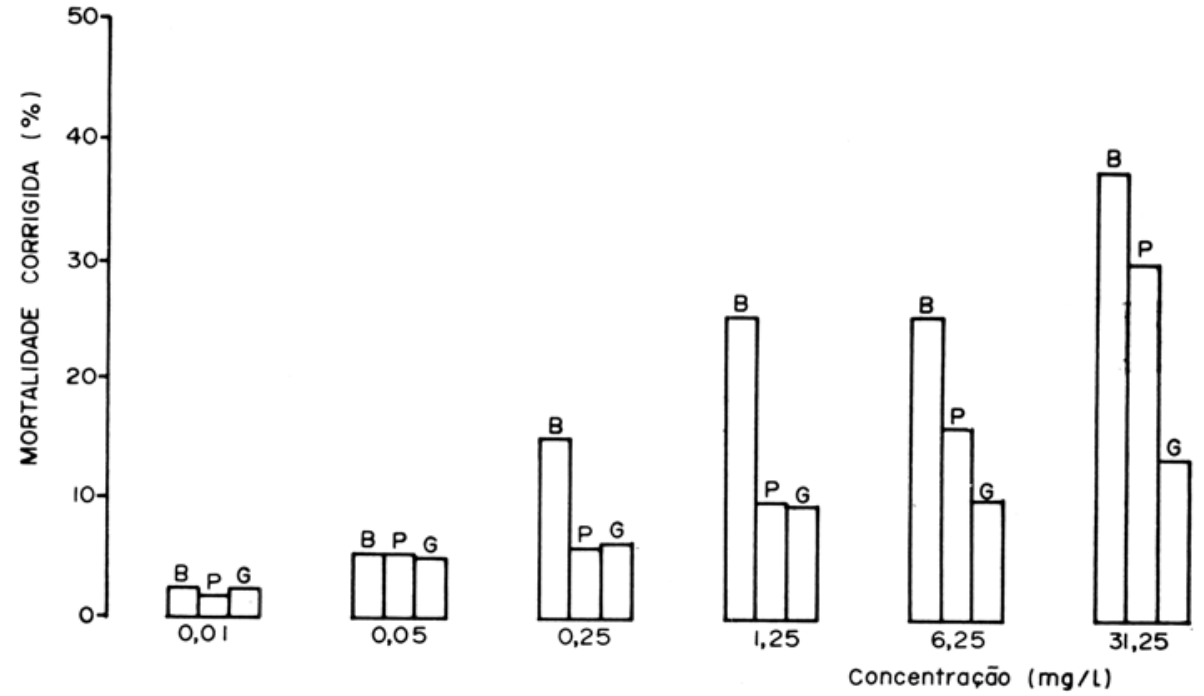

Figura 3. Mortalidade de S. punctata (G. F. W. Meyer) Thompson, após 8 dias.

$$
\begin{aligned}
& B=\text { butaclora } \\
& P=\text { propanila } \\
& G=\text { glifosato }
\end{aligned}
$$



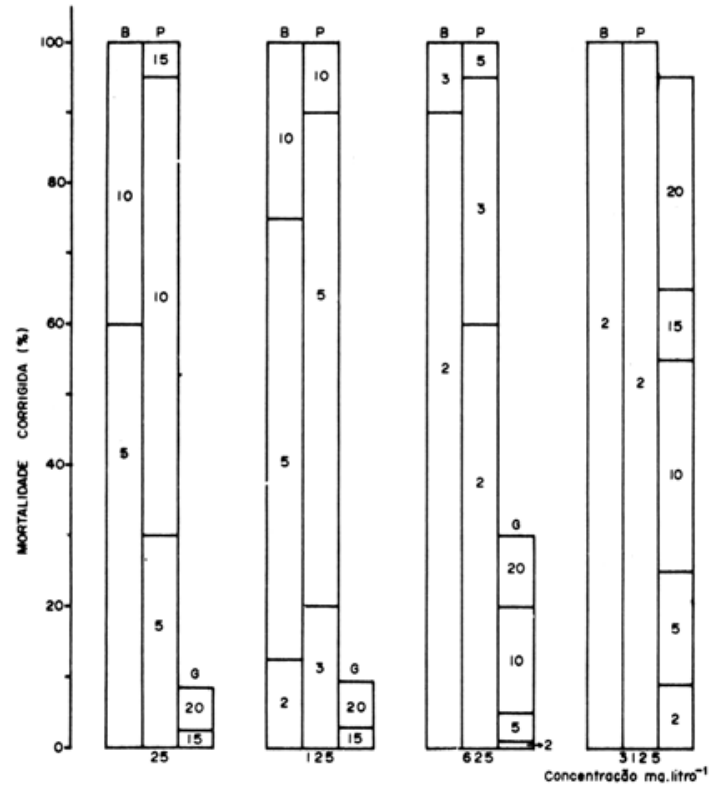

Figura 4. Mortalidade de S. punctata (G. F. W. Meyer) Thompson. Os números dentro das barras indicam o período em dias.

$$
\begin{aligned}
& \mathbf{B}=\text { butaclora } \\
& \mathbf{P}=\text { propanila } \\
& \mathbf{G}=\text { glifosato }
\end{aligned}
$$

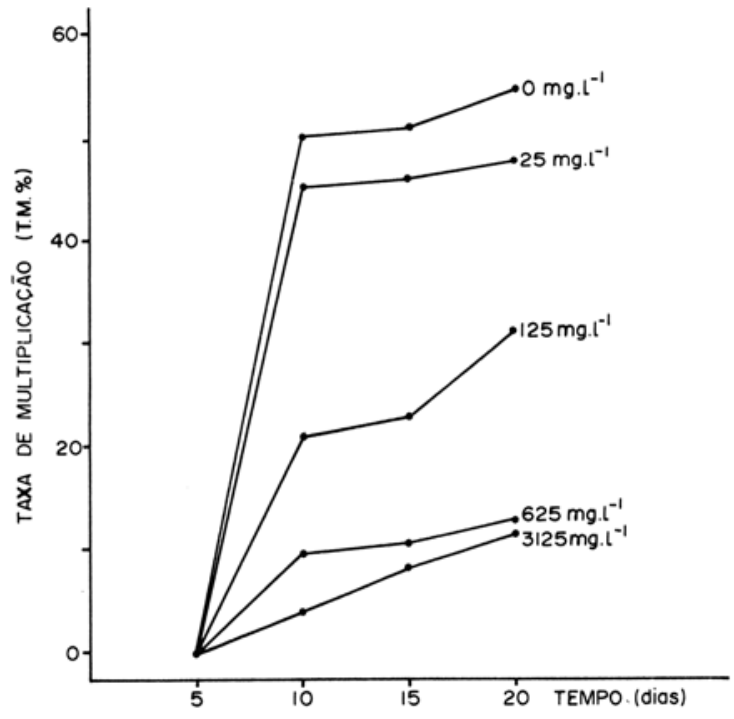

Figura 5. Crescimento de S. punctata (G. F. W. Meyer) Thompson, sob efeito do glifosato. 
TABELA 2 - Dados comparativos de dois métodos diferentes que determinam a taxa de multiplicação (TM) e o índice de mortalidade (I) de frondes de S. punctata tratadas com diversas concentrações de butaclora (B), propanila (P) e glifosato $(G)$.

\begin{tabular}{|c|c|c|c|c|c|c|c|c|c|c|c|c|c|}
\hline \multirow[t]{3}{*}{$\begin{array}{l}\text { Concentrações } \\
\left(\mathrm{mg} \mathrm{litro}{ }^{-1}\right)\end{array}$} & \multicolumn{6}{|c|}{$\begin{array}{c}\text { 1. ENSAIO } \\
\text { (Método Placas de Petri)* }\end{array}$} & \multicolumn{2}{|c|}{$\begin{array}{l}\text { Concentrações } \\
\left(\mathrm{mg} \mathrm{litro}^{-1}\right)\end{array}$} & \multicolumn{5}{|c|}{$\begin{array}{l}2 \text {. ENSAIO } \\
\text { (Método de copos de plásticos)** }\end{array}$} \\
\hline & \multicolumn{2}{|l|}{ B } & \multicolumn{2}{|c|}{$P$} & \multicolumn{2}{|c|}{ G } & & \multicolumn{2}{|l|}{ B } & \multicolumn{2}{|c|}{$\mathbf{P}$} & \multicolumn{2}{|r|}{ G } \\
\hline & $\mathrm{TM}$ & I & $\mathrm{TM}$ & I & $\mathrm{TM}$ & I & & $\mathrm{TM}$ & 1 & $\mathrm{TM}$ & I & $\mathrm{TM}$ & I \\
\hline \multirow[t]{6}{*}{0,01} & 65,1 & 2,5 & 84,2 & 1.5 & 83,0 & 2,5 & 25 & - & $O(2)$ & - & $0(2)$ & -- & $O(2)$ \\
\hline & & & & & & & & - & $0(3)$ & - & $0(3)$ & - & $O(3)$ \\
\hline & & & & & & & & - & $62,0(5)$ & - & $30(5)$ & 0 & $0(5)$ \\
\hline & & & & & & & & -1 & $100,0(10)$ & -9 & $95,5(10)$ & 46,0 & $0(10)$ \\
\hline & & & & & & & & - & $-(15)$ & - & $100(15)$ & 46,5 & $2,5(15)$ \\
\hline & & & & & & & & - & $-(20)$ & - & $-(20)$ & 47,5 & $9,0(20)$ \\
\hline \multirow[t]{5}{*}{0,05} & 58,3 & 6,0 & 83,0 & 6,0 & 83,0 & 5,5 & 125 & - & $13,0(2)$ & - & $0(2)$ & - & $O(2)$ \\
\hline & & & & & & & & $\overline{-}$ & $\begin{array}{r}13,0(3) \\
75,5(5)\end{array}$ & $\overline{-}$ & $\begin{array}{l}20(3) \\
90(5)\end{array}$ & $\overline{0}$ & $\begin{array}{l}0(3) \\
0(5)\end{array}$ \\
\hline & & & & & & & & - & $100,0(10)$ & - & $100(10)$ & 21,0 & $0(10)$ \\
\hline & & & & & & & & - & $-(15)$ & - & $-(15)$ & 23,0 & $3,0(15)$ \\
\hline & & & & & & & & - & $-(20)$ & - & $-(20)$ & 31,5 & $9,5(20)$ \\
\hline \multirow[t]{6}{*}{0,25} & 58,3 & 15,0 & 83,0 & 6,0 & 83,0 & 6,5 & 625 & - & $90,0(2)$ & - & $62,0(2)$ & - & $1,0(2)$ \\
\hline & & & & & & & & - & $100,0(3)$ & - & $96,0(3)$ & - & $1,0(3)$ \\
\hline & & & & & & & & - & $-(5)$ & - & $100,0(5)$ & 0 & $5,0(5)$ \\
\hline & & & & & & & & - & $-(10)$ & - & $-(10)$ & 9,5 & $20,0(10)$ \\
\hline & & & & & & & & - & $-(15)$ & - & $-(15)$ & 10,9 & $20,0(15)$ \\
\hline & & & & & & & & - & $-(20)$ & - & $-(20)$ & 12,5 & $30,0(20)$ \\
\hline \multirow[t]{6}{*}{1,25} & 28,0 & 25,0 & 76,0 & 10,0 & 79,0 & 9,5 & 3125 & - & $100(2)$ & - & $100(2)$ & - & $9,0(2)$ \\
\hline & & & & & & & & - & $-(3)$ & - & $-(3)$ & - & $9,0(3)$ \\
\hline & & & & & & & & - & $-(5)$ & - & $-(5)$ & 0 & $25,5(5)$ \\
\hline & & & & & & & & - & $-(10)$ & - & $-(10)$ & 3,5 & $55,5(10)$ \\
\hline & & & & & & & & - & $-(15)$ & - & $-(15)$ & 7,6 & $66,0(15)$ \\
\hline & & & & & & & & - & $-(20)$ & - & $-(20)$ & 11,0 & $100(20)$ \\
\hline 6,25 & 12,4 & 26,0 & 62,0 & 16,5 & 70,0 & 10,5 & & & & & & & \\
\hline 31,25 & 11,0 & 36,0 & 54,0 & 30,0 & 18,0 & 13,5 & & & & & & & \\
\hline
\end{tabular}

* Resultados após 8 dias

** Os números entre parênteses indicam o período em dias.

- Indica os resultados que não puderam ser coletados. 


\section{Conclusão}

Em relação ao $1^{\circ}$ ensaio, no qual utilizou-se placas de Petri e doses baixas dos três herbicidas pode-se concluir que:

1. As concentrações mais fortes $\left(6,25\right.$ e $\left.31,25 \mathrm{mg}^{\text {litro- }}{ }^{-1}\right)$ inibiram o crescimento da espécie em relação às demais concentrações.

2. O índice de mortalidade, entretanto, foi baixo nas concentrações mais fortes, não ultrapassando a $40 \%$.

3. Neste ensaio a butaclora foi o herbicida mais tóxico para a espécie, seguida da propanila e glifosato.

Quanto ao $2^{\circ}$ ensaio, no qual utilizou-se copos plásticos e doses elevada dos três herbicidas, pode-se concluir que:

1. O elevado índice encontrado para a mortalidade da butaclora e propanila, impediu a verificação da influêncịa destes herbicidas sobre a taxa de multiplicação. Por outro lado, a baixa toxicidade do glifosato permitiu verificar a taxa de multiplicação da espécie, com segurança por 20 dias.

2. A butaclora demonstrou ser o composto mais tóxico principalmente nas concentrações de 125,625 e 3.125 mg litro-1.

3. A propanila, nas concentrações de 625 e $3.125 \mathrm{mg}$ litro-1, provocou elevado índice de mortalidade, porém menor do que a butaclora.

4. O glifosato apresentou o efeito menos tóxico, não ultrapassando $9 \%$ de mortalidade em dois dias, no tratamento de $3.125 \mathrm{mg} \mathrm{litro}^{-1}$. Aos 20 dias, provocou $95 \%$ de mortalidade somente no tratamento $3.125 \mathrm{mg}$ litro-1; os demais tratamentos ficaram abaixo de $50 \%$, confirmando a baixa toxicidade deste herbicida para a espécie em estudo.

Tais conclusões reforçam o parecer de Offord (1946) quanto à importância da execução de ensaios sobre a toxidade dos herbicidas em lemnáceas, como subsídios na solução dos problemas práticos do controle das plantas aquáticas infestantes.

\section{Referências Bibliográficas}

ABBOTT, W.S. 1965 A Method of computing the effectiveness of an inseticide. J. Econ. Entomol. 18: 265-267.

BOWKER, D.W.; DUFFIELD, A.N. \& DENNY, P. 1980. Methods for the isolation esterilization and cultivation of Lemnaceae. Freshwat. Biol. 10(4): 385-388.

BRIAN, R.C. 1976. The History and classification of herbicides. In: AUDUS, L. J. (ed.), Herbicides; physiology, biochemistry, ecology. 2ed. London, Academic Press, V.1, cap. 1, p.7-8.

CAMARGO, P.N. 1986. Herbicidas Orgânicos: fundamentos químicos-estruturais. 1 ed. Manole, São Paulo. 275 p.

CHARPENTIER, S. \& GARNIER, J. 1986. Study of multiplication and colony formation in Spirodela polyrhiza L. Weeds Abstr. 35(1): 31.

CORRELL, D.S. \& CORRELL, H.B. 1975. Aquatic and wetland Plants of Southweste RN United States. Stanford University Press, Cahifornia. v.1, 856 p.

FRYER, J.D. \& MAKEPEACE, R.J. 1977 Weed Control. Handbook. London, Blackwell Scientific Publications. $510 \mathrm{p}$.

HANCE, R.J. \& McKONE, C.E. 1976, The Determination of herbicides. In: AUDUS, L.J. (ed.) Herbicides: physiology, biochemistry, ecology. 2ed. London, Academic Press. V. 2. cap. 14. p. 393-445.

HILLMAN, W.S. 1961. The Lemnaceae or duckweeds. A review of the descriptive and experimental literature. Bot. Rev. 27: 221-287.

HILLMAN, W.S. 1969 Lemna perpusilla Torr., Strain 6746. In: EVANS, L.T. (ed.) The Induction of flowering. Macmillan of Australia. cap. 7. p. 186-204. 
HUPPATZ, J.L. \& PHILLIPS, J.N. 1982. Cyanoacrylate herbicides. Weed Abstr. 31(8): 303.

LORENZI, H. 1982. Plantas daninhas do Brasil: terrestres, aquáticas, parasitas, tóxicas e medicinais. Nova Odessa SP. 423p.

MARGALEF, R. 1977. Ecologia. Ed. Omega, Barcelona, 951 p.

METHA, I. 1979. A note on the aquatic weed problem in the Rajasthan canal project. Biol. Abstr. 67 (11): 64632.

O'BRIEN, M.C. \& PRENDEVILLE, G.N. 1978. A Rapid sensitive biossay for determination of paraquat and diquat water. Weed Res. 18(5): 301-304.

OFFORD, H.R. 1946. Rapid estimation of the Phytocidal Action of Chemicals. Science 103(2677): 474-476.

PALM, C.E. 1968. Weed Control: Principles of Plant and Animal Pest Control. National Academy of Sciences, Washington, D.C. 471 p.

RADOSEVICH. S.R. \& HOLT, J.S. 1984. Weed Ecology: implications for vegetation management. Wiley - Intersciense Publication, John Wiley \& Sons, New York, Rochester, Brisbane, Toronto, Singapore 265 p.

RASOL, M.K. \& RENDIC, L. 1978. The Effect of some triazine derivatives on the growth and development of duckweeds. Biol. Abstr. 66(4): 24023.

ROMBACH, J. Effects of light and phytochrome in heterotrophic growth of Lemna minor L. Meded. Landb. Wageningen 76(1): 1-114, 1976.

SAGGERS, D.T. 1976. The Search for new herbicides. In: AUDUS, L.J. (ed.): Herbicides: physiology, biochemistry, ecology. 2ed. London, Academic Press, v. 2. Cap. 15. p. $447-473$.

SAHAI, R.; ROY, P.S.; WAJIH, S.A. Effect of certain herbicides on the growth performance of Spirodela polyrhiza. Weed. Abstr. 32(12): 356, 1983.

SHAW, W.C. \& SWANSON, C.R. The Relation of structure configuration to herbicidal properties and phytotoxicity of several carbamates and other chemicals. Weeds 2: 43-65, 1953.

SLOOFF, W. \& CANTON, J.H. 1984. Comparison of the susceptibility of 11 freshwater species to 8 chemical compounds: 2 (Semi) chronic toxicity test. Biol. Abstr. 77(8): 63932.

WAY, J.W. \& CHANCELLOR, R.J. 1976. Herbicides and higher plant ecology. In: AUDUS, L.J. (ed.) Herbicides: physiology, biochemistry, ecology. 2ed. London, Academic Press, v.2. cap. 12. p. 345-372. 